\title{
Hypercalcemia after the Discontinuation of Medroxyprogesterone Acetate
}

\author{
Erina Yuasa-Shibasaki, Sumiyasu Ishii, Shunichi Matsumoto, Takuya Tomaru, \\ Kazuhiko Horiguchi, Aya Osaki, Atsushi Ozawa, Nobuyuki Shibusawa, \\ Tetsurou Satoh and Masanobu Yamada
}

\begin{abstract}
:
A 39-year-old woman was admitted to our hospital with symptoms of general fatigue, nausea, and vomiting that appeared three months after she stopped seven years of medroxyprogesterone acetate (MPA) medication for endometrial stromal sarcoma. Laboratory tests demonstrated moderate hypercalcemia. Several tests demonstrated that she was suffering from adrenal insufficiency. Glucocorticoid supplementation decreased her calcium level to a normal range, indicating that hypercalcemia was induced by adrenal insufficiency. It was suggested that she was suffering from MPA-induced adrenal insufficiency, but hypocortisolemia was being compensated by a high dose of MPA; hypocortisolemia and hypercalcemia then became evident after MPA treatment was discontinued.
\end{abstract}

Key words: hypercalcemia, adrenal insufficiency, medroxyprogesterone acetate, glucocorticoid supplementation

(Intern Med 57: 545-549, 2018)

(DOI: 10.2169/internalmedicine.9036-17)

\section{Introduction}

Hypercalcemia is a relatively common problem. In most cases, it is induced by primary hyperparathyroidism or malignancy (1), but a wide variety of diseases can potentially cause elevated levels of serum calcium as well. Patients with mild or chronic hypercalcemia might be asymptomatic, but severe or acute hypercalcemia can sometimes result in a coma. Other manifestations include nausea, vomiting, constipation, polyuria, depression, and fatigue. The treatment is determined by both the severity and the etiology of hypercalcemia.

Adrenal insufficiency is a life-threatening disorder that can result from primary adrenal failure or secondary adrenal disease due to impairment of the hypothalamic-pituitary axis (2). Patients exhibit fatigue, weight loss, nausea, vomiting, dry skin, and hypoglycemia. Glucocorticoid supplementation is essential for such patients.

Medroxyprogesterone acetate (MPA) is commonly used as hormonal therapy for several diseases, including breast cancer, endometrial cancer, amenorrhea, and endometrial stromal sarcoma (3). High-dose MPA treatment can achieve long-term control of endometrial stromal sarcoma (4).

We herein report a case of hypercalcemia that emerged after discontinuation of MPA. Laboratory testing revealed adrenal insufficiency, which was suggested to be the result of long-term MPA treatment. We speculated that high-dose MPA administration had been compensating for adrenal insufficiency, and the symptoms became overt after discontinuation of MPA. Hypercalcemia appeared to be a manifestation of adrenal insufficiency, as glucocorticoid supplementation normalized the level of serum calcium.

\section{Case Report}

A 39-year-old woman was admitted to our hospital with complaints of general fatigue, nausea, and vomiting for the previous 3 months. She had undergone a hysterectomy because of an endometrial stromal sarcoma seven years earlier. 
Table 1. Laboratory Findings on Admission.

\begin{tabular}{|c|c|c|c|c|c|}
\hline Hematology & & Blood chemistry & & Hormones & \\
\hline Hematocrit & $43.8 \%$ & Total protein & $6.7 \mathrm{~g} / \mathrm{dL}$ & intact-PTH & $7.3 \mathrm{pg} / \mathrm{mL}$ \\
\hline Hemoglobin & $15.6 \mathrm{~g} / \mathrm{dL}$ & Albumin & $4.0 \mathrm{~g} / \mathrm{dL}$ & PTHrP & $<1.1 \mathrm{pmol} / \mathrm{L}$ \\
\hline Red blood cell & $493 \times 10^{4} / \mu \mathrm{L}$ & Aspartate aminotransferase & $56 \mathrm{IU} / \mathrm{L}$ & Calcitriol & $11 \mathrm{pg} / \mathrm{mL}$ \\
\hline Platelet & $19.8 \times 10^{4} / \mu \mathrm{L}$ & Alanine aminotransferase & $33 \mathrm{IU} / \mathrm{L}$ & Calcifediol & $9 \mathrm{ng} / \mathrm{mL}$ \\
\hline White blood cell & $5,100 / \mu \mathrm{L}$ & Lactate dehydrogenase & $195 \mathrm{IU} / \mathrm{L}$ & Calcitonin & $<5.0 \mathrm{pg} / \mathrm{mL}$ \\
\hline Neutrophil & $54.7 \%$ & Alkaline phosphatase & $272 \mathrm{IU} / \mathrm{L}$ & Thyrotropin & $9.52 \mu \mathrm{U} / \mathrm{mL}$ \\
\hline Eosinophil & $4.8 \%$ & $\gamma$-glutamyl transpeptidase & $33 \mathrm{IU} / \mathrm{L}$ & Free thyroxine & $1.32 \mathrm{ng} / \mathrm{dL}$ \\
\hline Basophil & $0.5 \%$ & Blood urea nitrogen & $16 \mathrm{mg} / \mathrm{dL}$ & Growth hormone & $0.3 \mathrm{ng} / \mathrm{mL}$ \\
\hline Monocyte & $9.7 \%$ & Creatinine & $1.12 \mathrm{mg} / \mathrm{dL}$ & IGF-1 & $110 \mathrm{ng} / \mathrm{mL}$ \\
\hline \multirow[t]{2}{*}{ Lymphocyte } & $11.3 \%$ & Sodium & $136 \mathrm{mEq} / \mathrm{L}$ & & \\
\hline & & Potassium & $3.0 \mathrm{mEq} / \mathrm{L}$ & Calcium metabolism & \\
\hline Coagulation & & Chloride & $93 \mathrm{mEq} / \mathrm{L}$ & Bone alkaline phosphatase & $26.5 \mu \mathrm{g} / \mathrm{L}$ \\
\hline Fibrinogen & $357 \mathrm{mg} / \mathrm{dL}$ & Calcium & $12.0 \mathrm{mg} / \mathrm{dL}$ & intact-P1NP & $478 \mu \mathrm{g} / \mathrm{L}$ \\
\hline Prothrombin time & $93 \%$ & Phosphorus & $3.5 \mathrm{mg} / \mathrm{dL}$ & TRACP-5b & $887 \mathrm{mU} / \mathrm{dL}$ \\
\hline APTT & $28.7 \mathrm{sec}$ & Glucose & $103 \mathrm{mg} / \mathrm{dL}$ & NTX & $131 \mathrm{nMBCE} / \mathrm{L}$ \\
\hline FDP & $3.8 \mu \mathrm{g} / \mathrm{mL}$ & $\mathrm{HbA} 1 \mathrm{c}$ & $5.3 \%$ & Urinary calcium & $158 \mathrm{mg} /$ day \\
\hline D-dimer & $2.1 \mu \mathrm{g} / \mathrm{mL}$ & Total cholesterol & $141 \mathrm{mg} / \mathrm{dL}$ & $\mathrm{FE}_{\mathrm{Ca}}$ & $1.23 \%$ \\
\hline
\end{tabular}

APTT: activated partial thromboplastin time, FDP: fibrin/ fibrinogen degradation product, HbA1c: hemoglobin A1c, PTH: parathyroid hormone, IGF-1: insulin-like growth factor 1, P1NP: N-terminal propeptide of type I procollagen, TRACP-5b: tartrate-resistant acid phosphatase form 5b, NTX: N-telopeptide of type I collagen, $\mathrm{FE}_{\mathrm{Ca}}$ : fractional excretion of calcium

Thereafter, she had been treated with $600 \mathrm{mg}$ of MPA as adjuvant therapy; MPA had been discontinued 3 months before the admission because no recurrence of the sarcoma had been observed. Her symptoms appeared soon after she stopped MPA medication, suggesting a relationship between the MPA withdrawal and her sickness. She was receiving furosemide and spironolactone because of cardiomyopathy, but was not taking any medication or dietary supplement that might have increase the serum calcium level on admission. She did not have any history of urinary stones.

Her blood pressure was slightly low $(84 / 63 \mathrm{mmHg})$, and her skin was dry. Laboratory tests demonstrated moderate hypercalcemia with normal phosphorus and albumin levels (Table 1). Her serum creatinine level was slightly high, and the levels of sodium, chloride, and potassium were low, but these abnormal findings were rapidly normalized after saline infusion and food intake, suggesting dehydration and loss of minerals by diuretics and vomiting. The levels of intact parathyroid hormone (PTH), PTH-related protein (PTHrP), calcitriol (1,25-dihydroxyvitamin $\mathrm{D}_{3}$ ), and calcifediol (25hydroxyvitamin $\mathrm{D}_{3}$ ) were low. Ultrasonography did not demonstrate parathyroid adenoma. Fractional excretion of calcium $\left(\mathrm{FE}_{\mathrm{Ca}}\right)$ was not low. She was not suffering from thyrotoxicosis. Markers for bone resorption were slightly elevated. No signs of malignant tumors were observed in her bones, as assessed by ${ }^{18}$ fluoro-deoxyglucose-positron emission tomography (FDG-PET) and bone scintigraphy. Serum protein electrophoresis did not suggest the presence of multiple myeloma.

In addition to hydration therapy, treatment with elcatonin lowered her calcium level, although it was still above the normal range, indicating that hypercalcemia was not solely due to dehydration. Her nausea and fatigue were alleviated but still persisted (Figure). Many types of disorders, including autoimmune diseases, infectious diseases and hormonal diseases such as infant hypothyroidism and adrenal insufficiency, are potential inducers of hypercalcemia, although these cases are not common (5). Among these diseases, we investigated whether or not she was suffering from adrenal insufficiency, because hypocortisolemia could explain all of her symptoms. Although the levels of serum cortisol and plasma corticotropin were within normal limits, the levels of urinary free cortisol and plasma dehydroepiandrosterone sulfate (DHEA-S) exhibited extremely low, suggesting adrenal insufficiency (Table 2A). Continuous glucose monitoring (CGM) revealed hypoglycemia during the nighttime, although she did not complain of any typical hypoglycemic symptoms, such as palpitations and sweating.

Corticotropin and cortisol are regarded as counterregulatory hormones in the hypoglycemic state and are usually upregulated during hypoglycemia. However, reactive stimulation was not observed when we measured the levels of these hormones in the morning during hypoglycemia. Her serum insulin level was low, indicating that hypoglycemia was not induced by excessive secretion of insulin. Provocative tests demonstrated that cortisol secretion was normally stimulated by corticotropin (Table 2B). A corticotropin-releasing hormone $(\mathrm{CRH})$ test demonstrated that corticotropin secretion was stimulated at a normal level, but that the peak of cortisol was not high enough considering the level of corticotropin present. In addition, the peak of corticotropin appeared to be slightly delayed, as the corticotropin level at $60 \mathrm{~min}$ utes was similar to that at 30 minutes (Table 2C). Magnetic resonance imaging (MRI) did not reveal any abnormal findings in the hypothalamus or pituitary gland. Calcification in the adrenal gland, which suggests adrenal tuberculosis, was 


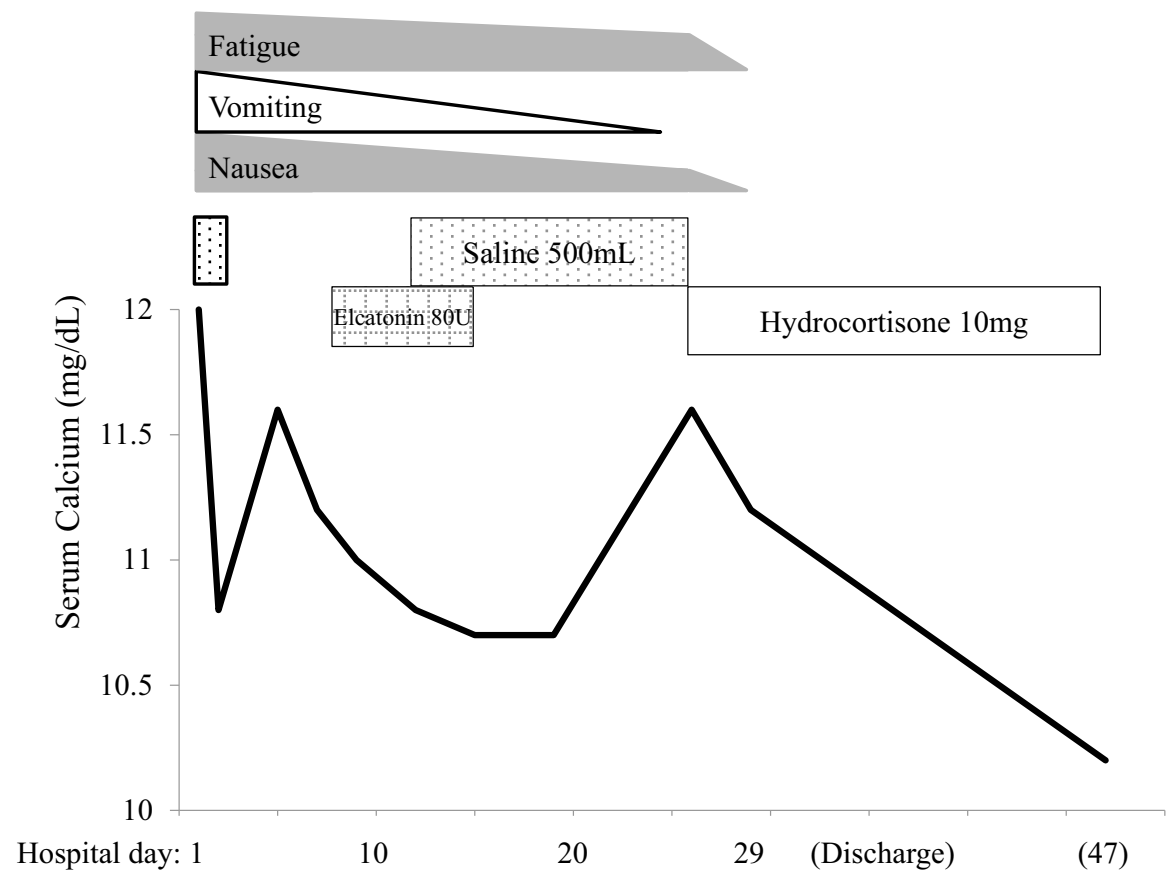

Figure. Schematic presentation of the clinical course.

Table 2. Adrenal Function.

\begin{tabular}{|c|c|c|c|}
\hline \multicolumn{4}{|l|}{ (A) } \\
\hline \multicolumn{2}{|l|}{ Adrenal function } & \multicolumn{2}{|c|}{ Hormones during hypoglycemia } \\
\hline Corticotropin & $20.8 \mathrm{pg} / \mathrm{mL}$ & Plasma glucose & $49 \mathrm{mg} / \mathrm{dL}$ \\
\hline Cortisol & $8.0 \mu \mathrm{g} / \mathrm{dL}$ & Insulin & $1.6 \mu \mathrm{U} / \mathrm{mL}$ \\
\hline DHEA-S & $30 \mathrm{ng} / \mathrm{mL}$ & C-peptide & $1.03 \mathrm{ng} / \mathrm{mL}$ \\
\hline \multicolumn{2}{|c|}{ (normal range: $230-2,660$ ) } & Corticotropin & $9.0 \mathrm{pg} / \mathrm{mL}$ \\
\hline Urinary free $\mathrm{c}$ & $10.9 \mu \mathrm{g} /$ day & Cortisol & $6.0 \mu \mathrm{g} / \mathrm{dL}$ \\
\hline
\end{tabular}

DHEA-S: dehydroepiandrosterone sulfate

(B) Corticotropin (ACTH) test

\begin{tabular}{lrrr}
\hline Time $(\mathrm{min})$ & 0 & 30 & 60 \\
Cortisol $(\mu \mathrm{g} / \mathrm{dL})$ & 23.8 & 34.7 & 42.3 \\
\hline
\end{tabular}

(C) Corticotropin-releasing hormone $(\mathrm{CRH})$ test

\begin{tabular}{lrrrrr}
\hline Time $(\min )$ & 0 & 30 & 60 & 90 & 120 \\
Corticotropin $(\mathrm{pg} / \mathrm{mL})$ & 13.0 & 52.6 & 51.6 & 33.4 & 18.2 \\
Cortisol $(\mu \mathrm{g} / \mathrm{dL})$ & 4.4 & 13.3 & 14.9 & 10.3 & 7.2 \\
\hline
\end{tabular}

not shown on computed tomography (CT). She tested negative for human immunodeficiency virus.

She was supplemented with hydrocortisone, and her symptoms rapidly disappeared (Figure). CGM demonstrated the recovery from nocturnal hypoglycemia. The serum calcium level decreased to the normal range without any other treatment, indicating that hypercalcemia had been induced by adrenal insufficiency. The levels of bone resorption markers, such as tartrate-resistant acid phosphatase form $5 b$ (TRACP-5b) and N-telopeptide of type I collagen (NTX), were high even after hypercalcemia disappeared, but these markers gradually decreased (Table 3 ). She has been free of hypercalcemia and other manifestation for more than one year. She still needs glucocorticoid supplementation, probably due to long-term adrenal deficiency.

\section{Discussion}

Understanding the etiology of hypercalcemia is essential for administering the proper treatment. Most cases are due to primary hyperparathyroidism or malignancy (1). However, it is not always easy to identify the reason for elevated levels of serum calcium, as many types of diseases may be responsible (6). In our case, the level of intact PTH was suppressed, indicating that the patient was not suffering from primary hyperparathyroidism or PTH-producing tumors. In 
Table 3. Time Course of Laboratory Data.

\begin{tabular}{lrrrr}
\hline Hospital days & 1 & 26 & $(47)$ & $(375)$ \\
\hline Calcium $(\mathrm{mg} / \mathrm{dL})$ & 12.0 & 11.6 & 10.2 & 9.8 \\
FE $_{\mathrm{Ca}}(\%)$ & 1.24 & & 1.16 & 0.55 \\
Bone alkaline phosphatase $(\mu \mathrm{g} / \mathrm{L})$ & 26.5 & & 34.1 & 15.8 \\
TRACP-5b (mU/dL) & 887 & & 1130 & 640 \\
NTX (nMBCE/L) & 131.0 & & 107.0 & 30.1 \\
Hemoglobin $(\mathrm{g} / \mathrm{dL})$ & 15.6 & 12.5 & 12.0 & 13.7 \\
Creatinine $(\mathrm{mg} / \mathrm{dL})$ & 1.12 & 0.64 & 0.57 & 0.55 \\
Sodium $(\mathrm{mEq} / \mathrm{L})$ & 136 & 138 & 142 & 142 \\
\hline
\end{tabular}

Hydrocortisone supplementation started on day 27.

$\mathrm{FE}_{\mathrm{Ca}}$ : fractional excretion of calcium, TRACP-5b: tartrate-resistant acid phos-

phatase form 5b, NTX: N-telopeptide of type I collagen

addition, $\mathrm{FE}_{\mathrm{Ca}}$ was not low, eliminating the possibility of familial hypercalciuric hypercalcemia, which is caused by a mutation in the calcium-sensing receptor gene (7). Humoral hypercalcemia of malignancy, in which malignant tumors produce PTHrP (8), was not likely because PTHrP was not detected in her serum. A low level of calcitriol excluded the possibility of activation of 1-alpha hydroxylase by lymphoma or granulomatous diseases, such as tuberculosis and sarcoidosis (9). The calcifediol level, as well as her medication history, did not show any evidence of vitamin D intoxication. FDG-PET and bone scintigraphy did not suggest any signs of osteolytic malignant diseases (8) or recurrence of endometrial stromal sarcoma. Multiple myeloma can also increase the serum calcium level, but serum protein electrophoresis showed negative results for the presence of this disease. Therefore, we considered rare causes of hypercalcemia (5).

Adrenal insufficiency is one of the diseases that can induce the elevation of the serum calcium level. It is reported that $6 \%$ of primary adrenal insufficiency cases exhibit hypercalcemia (2). The clinical manifestations of hypoadrenalism include fatigue, weight loss, nausea, vomiting, dry skin, and hypoglycemia, which are consistent with the symptoms of our case. Low levels of urinary free cortisol and plasma DHEA-S, and the nocturnal hypoglycemia demonstrated by CGM, supported the hypothesis that she was suffering from moderate hypoadrenalism, although her basal levels of serum cortisol and plasma corticotropin were normal. Cortisol secretion was normally stimulated by the administration of corticotropin. A CRH stimulation test suggested a delayed up-regulation of corticotropin with slightly weak activity, based on the peak level of cortisol. We did not perform an insulin tolerance test because we were able to measure the levels of corticotropin and cortisol during spontaneous hypoglycemia. The expected up-regulation of the pituitaryadrenal axis was not observed. Based on these findings, we speculate that our case was suffering from tertiary adrenal insufficiency, in which the hypothalamic function was disturbed. In addition to primary adrenal insufficiency, central adrenal insufficiency is also reported to induce hypercalcemia $(10,11)$.
The precise mechanisms though which adrenal insufficiency induces hypercalcemia are not yet fully understood. Multiple factors are suggested to be involved, including increased bone resorption and decreased renal calcium excretion due to dehydration (12-14). Consistent with these reports, the levels of bone resorption markers were elevated in our patient (Table 1). However, high bone resorption marker levels persisted in our patient, even after the serum calcium level was normalized (Table 3). Indeed, previous reports have not mentioned whether or not the levels of bone resorption markers were rapidly decreased. However, histological studies of the bones in patients with hypercalcemia induced by Addison's disease have shown no signs of bone resorption (13). Therefore, it remains unclear whether or not increased bone resorption really contributes to hypercalcemia. In addition, our patient was also suffering from dehydration, although diuretics and vomiting likely contributed as well. However, saline infusion to correct dehydration did not fully correct the hypercalcemia (Figure), consistent with previous reports (13). Transient thyrotoxicosis is suggested to be involved in hypercalcemia in corticotropin-deficient patients $(10,11)$, but this was not the case in our patient, as she presented with subclinical hypothyroidism. Supplementation with glucocorticoid normalized her serum calcium level, supporting the idea that her hypercalcemia was due to adrenal insufficiency.

It was not easy to identify the reason for adrenal insufficiency, as imaging studies did not suggest any causes for primary or central adrenal insufficiency. It has been reported that high-dose MPA can cause adrenal insufficiency (15). Therefore, we hypothesized that her history of MPA treatment was involved in the etiology. A high dose of MPA can result in both iatrogenic Cushing's syndrome and subsequent adrenal insufficiency at the same time $(16,17)$, because MPA and glucocorticoid are both derivatives of steroids and are structurally similar. Thus, she may have been suffering from MPA-induced adrenal insufficiency, but her hypocortisolemia was compensated by the high dose of MPA, so hypocortisolemia and hypercalcemia only became evident after MPA treatment was discontinued.

Hypercalcemia was reported in four breast cancer patients 
with bone metastasis who were treated with MPA (18). The authors suggested some effects of MPA on bone lesions, although the mechanism was unknown. This does not seem to be the case in our patient, as she did not have any bone tumors. Those four patients might have also been suffering from adrenal insufficiency, as two of them recovered from hypercalcemia after the administration of steroids. Why our patient exhibited hypercalcemia despite hypercalcemia not being common in patients with adrenal insufficiency and the degree of her hypocortisolemia not being very severe is unclear, as the mechanisms underlying hypocortisolemiainduced hypercalcemia have yet to be elucidated, as discussed above. One hallmark of our case is the sudden onset of hypocortisolism after long-term treatment with MPA, which exhibits glucocorticoid-mimetic action. Indeed, hypercalcemia was reported in a patient who had undergone glucocorticoid withdrawal after unilateral adrenalectomy (19). In that case, hypercalcemia was due in part to increased renal tubular reabsorption of calcium as a result of glucocorticoid withdrawal, which is consistent with the present case. Therefore, MPA withdrawal might have contributed to the elevation of serum calcium levels in our case.

To our knowledge, this is the first report of hypercalcemia emerging after the discontinuation of MPA. Adrenal insufficiency induced by MPA was involved in the mechanism. Glucocorticoid supplementation should therefore be considered when a high dose of steroid-type hormone therapy is withdrawn.

The authors state that they have no Conflict of Interest (COI).

\section{References}

1. Lafferty FW. Differential diagnosis of hypercalcemia. J Bone Miner Res 6 (Suppl 2): S51-S59; discussion S61, 1991.

2. Charmandari E, Nicolaides NC, Chrousos GP. Adrenal insufficiency. Lancet 383: 2152-2167, 2014.

3. Pink D, Lindner T, Mrozek A, et al. Harm or benefit of hormonal treatment in metastatic low-grade endometrial stromal sarcoma: single center experience with 10 cases and review of the literature. Gynecol Oncol 101: 464-469, 2006.

4. Mizuno M, Yatabe $Y$, Nawa A, Nakanishi T. Long-term medroxyprogesterone acetate therapy for low-grade endometrial stromal sarcoma. Int J Clin Oncol 17: 348-354, 2012.

5. Jacobs TP, Bilezikian JP. Clinical review: rare causes of hypercalcemia. J Clin Endocrinol Metab 90: 6316-6322, 2005.
6. Endres DB. Investigation of hypercalcemia. Clin Biochem 45 : 954-963, 2012.

7. Pollak MR, Brown EM, Chou YH, et al. Mutations in the human $\mathrm{Ca}(2+)$-sensing receptor gene cause familial hypocalciuric hypercalcemia and neonatal severe hyperparathyroidism. Cell 75: 12971303, 1993.

8. Mirrakhimov AE. Hypercalcemia of malignancy: an update on pathogenesis and management. N Am J Med Sci 7: 483-493, 2015.

9. Adams JS, Hewison M. Extrarenal expression of the 25hydroxyvitamin D-1-hydroxylase. Arch Biochem Biophys 523: 95102, 2012.

10. Grossmann M, Fuller P, Hunter A, Teede H. Isolated ACTH deficiency presenting as severe hypercalcaemia. Clin Endocrinol (Oxf) 66: 603-604, 2007.

11. Vasikaran SD, Tallis GA, Braund WJ. Secondary hypoadrenalism presenting with hypercalcaemia. Clin Endocrinol (Oxf) 41: 261264, 1994.

12. Fujikawa M, Kamihira K, Sato K, Okamura K, Kidota S, Lida M. Elevated bone resorption markers in a patient with hypercalcemia associated with post-partum thyrotoxicosis and hypoadrenocorticism due to pituitary failure. J Endocrinol Invest 27: 782-787, 2004.

13. Montoli A, Colussi G, Minetti L. Hypercalcaemia in Addison's disease: calciotropic hormone profile and bone histology. J Intern Med 232: 535-540, 1992.

14. Muls E, Bouillon R, Boelaert J, et al. Etiology of hypercalcemia in a patient with Addison's disease. Calcif Tissue Int 34: 523-526, 1982.

15. van Veelen H, Willemse PH, Sleijfer DT, van der Ploeg E, Sluiter WJ, Doorenbos H. Mechanism of adrenal suppression by highdose medroxyprogesterone acetate in breast cancer patients. Cancer Chemother Pharmacol 15: 167-170, 1985.

16. Krueger RB, Hembree W, Hill M. Prescription of medroxyprogesterone acetate to a patient with pedophilia, resulting in Cushing's syndrome and adrenal insufficiency. Sex Abuse 18: 227-228, 2006.

17. Seo Y, Jeong EG, Kim ES. Cushing's syndrome with adrenal suppression and masked hyperandrogenism by high-dose medroxyprogesterone acetate for treatment of endometrial cancer in a young woman with polycystic ovarian syndrome. Endocrine 50: 519-521, 2015.

18. Kaufman RJ, Rothschild EO, Escher GC, Myers WP. Hypercalcemia in mammary carcinoma following the administration of a progestational agent. J Clin Endocrinol Metab 24: 1235-1243, 1964.

19. Suzuki K, Nonaka K, Ichihara K, et al. Hypercalcemia in glucocorticoid withdrawal. Endocrinol Jpn 33: 203-209, 1986.

The Internal Medicine is an Open Access article distributed under the Creative Commons Attribution-NonCommercial-NoDerivatives 4.0 International License. To view the details of this license, please visit (https://creativecommons.org/licenses/ by-nc-nd/4.0/).

(C) 2018 The Japanese Society of Internal Medicine Intern Med 57: 545-549, 2018 